Psychological Medicine, 1991, 21, 565-575

Printed in Great Britain

EDITORIAL

\title{
The neurodevelopmental basis of sex differences in schizophrenia ${ }^{1}$
}

Male schizophrenics tend to manifest a severe form of the disease, characterized by early onset, poor pre-morbid adjustment, 'typical' and 'negative' symptoms, and poor outcome; they are more likely than their female counterparts to have a history of pre- or peri-natal complications, and to exhibit structural brain abnormalities. The most plausible explanation for these differences is that more male than female schizophrenics have a form of disease due to neurodevelopmental anomaly. This hypothesis also accounts for the excess of males in strictly defined schizophrenic cohorts, and in those who present before 30 years of age. In contrast, many later-onset females diagnosed 'schizophrenic' have more in common, aetiologically, with affective psychosis than schizophrenia. Thus, much of the contemporary confusion about schizophrenia results from the conflation of two separate disorders, one commonest in young males and the other in older females.

There have been many reports in the literature of differences in the characteristic of schizophrenia in males and females. The explanatory hypotheses proposed have mainly been in terms of the different social roles of men and women, though some authors have suggested that antidopaminergic properties of oestrogens may be 'protective' in females. This editorial argues that a neurodevelopmental perspective has greater explanatory power for the male-female differences in schizophrenia.

\section{GENDER DIFFERENCES}

\section{Epidemiology}

The best replicated gender difference in schizophrenia is the tendency for males to manifest the disease at an earlier age (Lewine, 1981, 1988; Angermeyer \& Kuhn, 1988). This finding is robust to the diagnostic system used (Lewine et al. 1981; Shimizu et al. 1988 a; Goldstein et al. 1989). Furthermore, it is not a result of differences in help-seeking behaviour between male and female schizophrenics or their families, or a consequence of differences in social role-expectation or marital status (Loranger, 1984; Angermeyer, 1985; Lewine, 1988; Riecher et al. 1989; Häfner et al. 1989).

Loranger (1984) has pointed out that the age distribution curves for schizophrenia are not isomorphic, and that some female patients manifest the disease in adolescence; thus the appearance of the disease is delayed in 'some but not all women'. This is represented in Fig. 1, which shows first admission rates for schizophrenia by sex, for England in 1984. It has usually been accepted that the greater number of late-onset females eventually 'balance out' the early males excess (e.g. Rosenthal, 1970; Dohrenwend \& Dohrenwend, 1976; Flor-Henry, 1985; Häfner, 1987). However, some recent data suggest that the overall sex incidence may not be equal. For example, in England the overall first admission rate for schizophrenia (ICD code 295) for 1984 was 6.6 per 100000 for males, and only 5.1 per 100000 for females (Government Statistical Office, 1986). Higher rates in males have also been reported by Strömgren (1987) and Häfner et al. (1989) in Denmark, Babigian (1975) in the USA, and in most centres participating in the WHO collaborative study (Sartorius $e t$ al. 1986). Furthermore, the application of stringent diagnostic criteria to cohorts of schizophrenics results in an even greater male preponderance (Lewine et al. 1984; Katschnig \& Lenz, 1988). This has also been shown in population-based studies. For example, Cooper et al. (1987) reported an annual incidence of DSM-III defined schizophrenia in Nottingham of 7 per 100000 for women, but 17 per 100000 for men. In Montreal, Nicole et al. (1990) reported an annual incidence of DSM-III-R

\footnotetext{
1 Address for correspondence: Professor Robin M. Murray, Institute of Psychiatry, De Crespigny Park, Denmark Hill, SE5 8AF.
} 


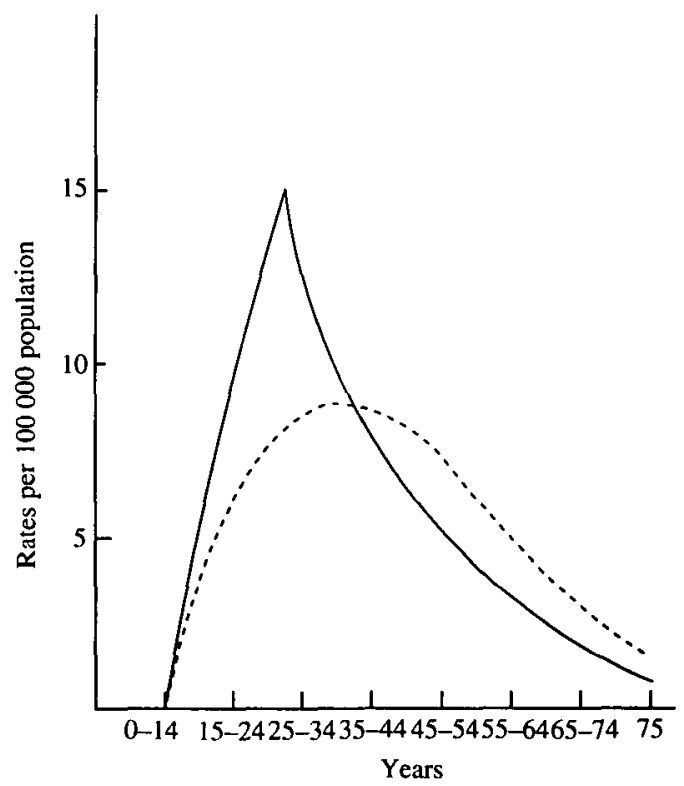

FIG. 1. First admission rates for schizophrenia by sex, for England, 1984 (source: Statistical Bulletin of Department of Health and Social Security, Government Statistical Office, 1986). (-, Males; ---, females.)

schizophrenia of 2.5 per 100000 for women and 6.9 per 100000 for men; the low rates in this study may be due to calculations being based only on patients admitted to hospital.

\section{Pre-morbid characteristics}

Many studies have suggested that schizophrenic males exhibit poorer pre-morbid social competence than do females (see Zigler \& Levine, 1973; Zigler et al. 1977; Klorman et al. 1977; Lewine, 1981). Offord \& Cross (1969) reviewed such studies and concluded that there was a correlation between 'disturbed' behaviour in childhood and early illness-onset; there was also an association between the latter and minimal brain dysfunction. The evidence from child guidance clinics is that attenders who go on to develop schizophrenia are mostly male, and show a mixture of antisocial and emotional problems in childhood (Garmezy, 1974; Zeitlin, 1986). Males are also over-represented among cohorts of 'schizoid' children (Wolff \& Chick, 1980), such children being considered prone to the later development of schizophrenia (see Gunderson \& Siever, 1985; Kendler, 1985).

Few studies have included a control group. However, Foerster et al. (1991a) compared schizophrenics and affective psychotics, and found that male schizophrenics had exhibited more abnormalities of pre-morbid personality and poorer pre-morbid social adjustment than female schizophrenics and both male and female affective psychotic patients. Importantly, this held true even in early childhood, a finding which precludes the possible confounding effect of earlier onset of psychosis in males.

Similar sex differences have been reported in pre-morbid IQ. Thus, Offord (1974) reported low pre-morbid IQ and poor school performance among male, but not female, schizophrenics. Aylward et al. (1984) reviewed the literature and concluded: 'Pre-morbid IQ deficit may be an exclusive, or more pronounced characteristic of schizophrenic males'. This gender difference in pre-morbid IQ was also found in a study of offspring of schizophrenic mothers (Rieder et al. 1977); 'soft' neurological signs (clumsiness, incoordination) and hyperactivity were also more prevalent among males in this 'at risk' group (Rieder \& Nichols, 1979). 


\section{Presentation and outcome}

Male schizophrenics are more likely to exhibit 'typical' schizophrenic symptomatology, with a tendency to withdrawal and passivity, while females more often manifest 'atypical' features, including a strong affective component (see Lewine, 1981 ; Goldstein \& Link, 1988). Furthermore, a number of studies have found males more likely to exhibit 'negative' features (Kay et al. 1986; Goldstein \& Link, 1988; Nasrallah \& Wilcox, 1989; Haas et al. 1989), though not all have concurred (reviewed by Pogue-Geile \& Zubin, 1988).

Few studies have specifically addressed gender differences in neuroleptic response in schizophrenics. However, female schizophrenics appear generally to respond more favourably to neuroleptic medication than do their male counterparts (Goldberg et al. 1966; Hogarty et al. 1974; Goldstein et al. 1978; and reviewed by Seeman, 1986); they also require lower doses of neuroleptics, at least prior to the menopause (Seeman, 1983, 1986).

Angermeyer et al. (1989) reviewed 50 studies reporting on gender and hospital treatment of schizophrenics. These studies differed widely in methodology and thus direct comparison was difficult, and findings inconsistent. A number of the studies reported no gender differences in hospital treatment. However, in almost all those studies which did report gender differences, women fared better in terms of rate of rehospitalization, number of admissions, and length of hospital stay. In their own careful study, Angermeyer et al. (1989) confirmed these impressions.

Seeman (1986), who reviewed the early-1980s literature concerning gender differences in social outcome of schizophrenics, again encountered difficulties in comparing studies which had employed varying methodology and different diagnostic criteria for schizophrenia. However, she concluded that overall 'schizophrenic women live better than schizophrenic men'. A number of more recent studies (e.g. Shepherd et al. 1989; Goldstein et al. 1989) concur.

\section{Summary}

It is clear that males are prone to a more severe form of schizophrenia than are females; age of onset is earlier, relapses more frequent and more severe, and response to neuroleptic medication less favourable. Male schizophrenics are more likely to show poor pre-morbid competence and low IQ, and are less well adjusted, socially and occupationally, than their female counterparts. In terms of the illness itself, males are more prone to 'typical' schizophrenic symptomatology, with a tendency to be withdrawn and passive, while females exhibit more affective features. Furthermore, some studies suggest that there is an overall excess of males among schizophrenics; what is certainly true is that there is an excess of males among those schizophrenics with a severe form of illness, as defined by restrictive operational criteria (see Lewine, 1988).

\section{EXPLANATORY THEORIES}

In seeking to explain why males are prone to a more severe form of schizophrenia, previous authors have implicated, inter alia: (i) more severe role-stresses in males (see Rosenthal, 1962; Farina et al. 1963; Lewine, 1981; Seeman, 1985; Al-Issa, 1985); (ii) social protective factors in females, for example less active courting behaviour, and less career-stress (Seeman, 1985); (iii) biological factors, specifically a 'triggering' effect of androgens in the male (see Loranger, 1984; Al-Issa, 1985), or a 'protective' effect of oestrogens in the female (see Seeman, 1985; De Lisi et al. 1989). However, as Lewine (1988) has pointed out, such hypotheses do not seek to explain the primary cause of schizophrenia, but rather to account for the earlier manifestation in males, given that schizophrenia will occur. We suggest that a neurodevelopmental perspective not only provides a causal explanation for the early-onset, severe schizophrenia to which males are more prone, but also takes into account recent evidence regarding the structural brain abnormalities found in some schizophrenics. 


\section{Structural brain abnormalities}

Non-invasive investigations of the brain in schizophrenia have been widely undertaken. The consensus of computerized tomographic (CT) studies is that schizophrenics tend to have increased ventricle-brain ratios (VBR) compared with normals (reviewed by Shelton \& Weinberger, 1986). Such changes are non-progressive, present at the onset of illness, and are associated with poor premorbid function (Pearlson et al. 1985; Nasrallah et al. 1986; Turner et al. 1986). More recently, magnetic resonance imaging (MRI) studies have shown smaller temporal lobe structures in schizophrenics (Johnstone et al. 1989 a; Suddath et al. 1990). Post-mortem studies of the brains of schizophrenics show abnormalities in the hippocampal region (Bogerts et al. 1985; Brown et al. 1986; Jakob \& Beckmann, 1986). No gliosis accompanies these lesions, suggesting that they originate in utero or in early infancy, possibly through genetically-mediated arrest of cell migration or pre- or peri-natal environmental insult (Jakob \& Beckmann, 1986; Lewis, 1989; Gill et al. 1989). The exact clinical significance of such lesions is unclear, but Randall (1983) and subsequently Weinberger (1987) have proposed that a fixed brain lesion, incurred at an early age, might manifest itself through an interaction with 'normal brain maturational events that occur much later'.

Numerous studies have demonstrated that a history of pre- and peri-natal hazards (collectively termed obstetric complications) is more common in schizophrenics than in normal subjects and in other psychiatric patients; this has been shown both in retrospective studies which rely on maternal interviews, and in those fewer studies which have examined contemporaneous birth records (Murray \& Lewis, 1987; McNeil, 1988; Lewis et al. 1988; O'Callaghan et al. 1988, 1990). Thus, there is little doubt that obstetric complications are associated with later schizophrenia; whether these (detectable) obstetric events are of aetiological importance in themselves, or whether they are themselves a consequence of earlier (undetectable) events, is unclear. What is undisputed is that schizophrenics with a history of obstetric complications present earlier than those without such a history (De Lisi et al. 1987; O'Callaghan et al. 1988; Owen et al. 1988); and a number of studies have shown that such patients are more likely to exhibit ventricular enlargement (Lewis \& Murray, 1987; Murray et al. 1988; Lewis et al. 1988; Pearlson et al. 1989), though not all have concurred (Nimgoankar et al. 1988).

\section{Brain abnormalities in schizophrenic males}

In schizophrenic populations, males are more likely to have a history of obstetric complications than are females (Pearlson et al. 1985; Wilcox \& Nasrallah, 1987; Owen et al. 1988; Foerster et al. $1991 \mathrm{~b}$ ). This is consonant with the fact that structural brain anomalies have been reported more commonly in male than female schizophrenics (see Table 1). For example, Andreasen et al. (1989) showed that male schizophrenics had significantly larger ventricles than normal males, but no such difference could be found between female schizophrenics and normal females. Similarly, Bogerts $e t$ al. $(1990 a)$, in a MRI study of first-episode schizophrenics, found smaller hippocampal volume on the left side only in male patients. Moreover, neuropathological abnormalities also appear to be more common in male schizophrenics. For example, Bogerts et al. (1990 b) found hippocampal volume to be significantly reduced in male, but not female, schizophrenics. Many of these studies have small sample-sizes, and the results need replication in studies specifically designed to assess gender differences; however, the available studies point in a consistent direction.

There has been considerable controversy over the clinical correlates of structural brain abnormalities in schizophrenia. However, the characteristics most frequently associated with increased ventricular size have been cognitive impairment, poor pre-morbid adjustment, more negative symptomatology, poor clinical outcome, poor employment record, and poor response to neuroleptics (for references, see Crow, 1985; Pearlson et al. 1989). We have already noted that each of these is more typical of male than female schizophrenics. Furthermore, Haas et al. (1989) have delineated male patients as being particularly likely to exhibit negative symptoms, poor pre-morbid adjustment, and poor cognition in association with increased ventricular size. Similarly, Goldstein 
Table 1. Gender differences in structural brain anomalies in schizophrenic samples

\begin{tabular}{|c|c|c|c|}
\hline Studies & No. & Measure & Findings \\
\hline \multicolumn{4}{|l|}{ CT scan studies } \\
\hline Reveley (1988) & $\begin{array}{l}35 \mathrm{M} \\
16 \mathrm{~F}\end{array}$ & VBR & $\begin{array}{l}\text { Increased VBR in } 16 \mathrm{M} \\
\text { and } 3 \mathrm{~F} \text {. }\end{array}$ \\
\hline Vita et al. (1988) & $\begin{array}{l}74 \mathrm{M} \\
50 \mathrm{~F}\end{array}$ & $\begin{array}{l}\text { Cortical } \\
\text { atrophy }\end{array}$ & Atrophy in $30 \mathrm{M}$ and $11 \mathrm{~F}$. \\
\hline \multirow[t]{2}{*}{ Pearlson et al. (1989) } & $\begin{array}{l}33 \mathrm{M} \\
57 \mathrm{~F}\end{array}$ & VBR & VBR $>2$ s.D. in $9 \mathrm{M}$ and $5 \mathrm{~F}$. \\
\hline & & Brain slice area & $\begin{array}{l}\text { Absence of expected relationship } \\
\text { between height and brain size in } \\
\text { males only. }\end{array}$ \\
\hline Haas et al. (1989) & $\begin{array}{l}25 \mathrm{M} \\
25 \mathrm{~F}\end{array}$ & VBR & $\begin{array}{l}\text { Males showed increased } \\
\text { VBR in association with poor } \\
\text { pre-morbid competence, negative } \\
\text { symptoms and cognitive deficits. }\end{array}$ \\
\hline Andreasen et al. (1989) & $\begin{array}{l}65 \mathrm{M} \\
43 \mathrm{~F}\end{array}$ & VBR & $\begin{array}{l}>2 \text { s.D.: } M+F=6 \% \\
M \text { alone }=19 \% \\
>1 \text { s.D.: } M+F=28 \% \\
M \text { alone }=43 \%\end{array}$ \\
\hline Harvey et al. (1990) & $\begin{array}{l}24 \mathrm{M} \\
13 \mathrm{~F}\end{array}$ & $\begin{array}{l}\text { VBR } \\
\text { LVA }\end{array}$ & $\begin{array}{l}M: 7 \cdot 3 ; F: 5.9 \\
M: 11 \cdot 6 ; F: 8.5\end{array}$ \\
\hline \multicolumn{4}{|l|}{ MRI studies } \\
\hline Andreasen $e t$ al. (1986) & $\begin{array}{l}28 \mathrm{M} \\
10 \mathrm{~F}\end{array}$ & $\begin{array}{l}\text { Frontal } \\
\text { cerebral and } \\
\text { cranial area }\end{array}$ & $\begin{array}{l}\text { All measures smaller } \\
\text { and disproportionate to height in } \\
\text { males only. }\end{array}$ \\
\hline Lewine et al. (1989) & $28 \mathrm{M}+\mathrm{F}$ & $\begin{array}{l}\text { Various } \\
\text { structures }\end{array}$ & $\begin{array}{l}\text { Higher rate of anomalies in males } \\
(28 \%) v \text {. females }(0 \%) \text {. }\end{array}$ \\
\hline Johnstone et al. $(1989 a)$ & $\begin{array}{l}15 \mathrm{M} \\
6 \mathrm{~F}\end{array}$ & $\begin{array}{l}\text { Temporal horn } \\
\text { area }\end{array}$ & Greater in males \\
\hline Bogerts et al. $(1990 a)$ & $\begin{array}{l}22 \mathrm{M} \\
12 \mathrm{~F}\end{array}$ & $\begin{array}{l}\text { Various } \\
\text { structures }\end{array}$ & $\begin{array}{l}\text { Smaller left } \\
\text { hippocampus in males only. }\end{array}$ \\
\hline
\end{tabular}

VBR $=$ Ventricular brain ratio $; \mathrm{LVA}=$ Left ventricle area $;$ s.D. = standard deviation $; M=$ male, $F=$ female.

et al. (1990), using latent class analysis, found males to be more prone to a form of disease characterized by deficit symptoms, poor pre-morbid adjustment, winter birth (suggestive of environmental insult), and low familial risk for schizophrenia.

An excess of mild dysmorphic features, suggestive of abnormal foetal development, has been described in schizophrenic populations (Guy et al. 1983; Green et al. 1989). Green et al. (1989) found that males with poor pre-morbid functioning were particularly likely to exhibit dysmorphic features, while Waddington et al. (1990) reported an association between such anomalies and male sex, cognitive dysfunction, and obstetric complications.

\section{Cerebral laterality}

Left temporal lobe dysfunction appears to be of particular importance in schizophrenia; electroencephalographic (Flor-Henry, 1985), auditory evoked potential (Morstyn et al. 1983), and neurochemical (Reynolds, 1983) investigations have attested to this. Moreover, CT (Reveley et al. 1987), MRI (Johnstone et al. $1989 a$; Bogerts et al. 1990 b; Suddath et al. 1990), and neuropathological (Brown et al. 1986; Crow et al. 1989) studies have revealed structural anomalies of the left temporal lobe in some schizophrenics.

The brain is, to an extent, capable of 'compensating' for early unilateral brain damage. Thus, a lesion in the left hemisphere tends to result in right-hemisphere dominance and 'pathological lefthandedness' (Satz, 1972). Clinically, this is evidenced by high rates of non-right-handedness in individuals who were 'at risk' of obstetric hazard. For example, O'Callaghan et al. (1987) and Ross et al. (1987) showed a correlation between very low birth weight and non-right-handedness. The latter group also showed that non-right-handers had lower IQ and more language delays. In a group 
of schizophrenic patients, Seeman (1985) reported an association between left-handedness and lengthy maternal labour, suggestive of birth injury.

Although attempts to assess cerebral laterality in schizophrenics have met with limited success (see Nasrallah et al. 1981; Merrin, 1984), left-handedness and crossed dominance have been associated with early onset of illness (Piran et al. 1982); inferior social competence (Merrin, 1984); more negative symptomatology (Andreasen et al. 1982); and increased VBR and poor performance on neuropsychological tests (Katsanis \& Iacono, 1989). Lewine et al. (1989) found a correlation between clinical anomalies, reversed visual field preference, and MRI abnormalities in male schizophrenics. All this suggests that 'pathological' left-sided hand and eye preference may be associated with developmental insult and a severe form of disease to which males are more prone.

\section{MALE SUSCEPTIBILITY TO NEURODEVELOPMENTAL DISORDERS}

The main neurodevelopmental disorders are all more common in males than in females. Table 2 shows that estimates of the male: female ratio in such conditions range from 1.6:1 for severe mental retardation through 2.5:1 for autism to 3.75:1 for Asperger's Syndrome. This compares with a ratio of 2.3:1 among schizophrenics presenting before 25 years quoted by Rosenthal (1970), and $2 \cdot 1: 1$ for first admissions for schizophrenia between ages 20 and 24 years in England in 1984 (Government Statistical Office, 1986).

Table 2. Sex ratio in developmental disorders

\begin{tabular}{llc}
\hline \hline Disorder & Authors & Male: female ratio \\
\hline Dyslexia & Rutter \& Tizard, 1970 & $3 \cdot 3: 1$ \\
Autism & Bryson et al. 1988 & $2 \cdot 5: 1$ \\
Stuttering & Andrews \& Harris, 1964 & $2 \cdot 4: 1$ \\
Asperger's Syndrome & Wing, 1981 & $3 \cdot 75: 1$ \\
Severe mental retardation & Broman et al. 1987 & $1 \cdot 6: 1$ \\
\hline
\end{tabular}

Goodman (1990) has reviewed the characteristics of neurodevelopmental disorders. In addition to boys being more vulnerable, he points out that such disorders $(a)$ are over-represented among individuals with brain abnormalities; $(b)$ show an association with pre- and peri-natal complications; and $(c)$ have increased rates of left-handedness. It will not have escaped the reader that these have all been said of early-onset schizophrenia.

Why are males more prone to neurodevelopmental impairment? Geschwind \& Galaburda (1985) claim that males are more prone to obstetric hazards, but the evidence is flimsy. Certainly, males are more susceptible to both the short- (Yu et al. 1986) and long-term (Hadders-Algra et al. 1986) consequences of such hazards. For example, low birth weight males are more likely than their female equivalents to (a) develop intra- and peri-ventricular haemorrhage (Amato et al. 1987), and (b) experience long-term adverse neurological deficit (Rantakallio \& von Wendt, 1985); in rats at least, males are more likely to have behavioural/learning problems after perinatal insult (Grimm \& Freider, 1985).

The pace of cerebral development is slower in males than females (Taylor, 1969; Seeman, 1989). Thus, the male brain may be susceptible to environmental adversity for a longer period than the more rapidly-maturing female brain (Seeman, 1989). Also, in rats (see Diamond, 1989) and probably humans (e.g. Thatcher et al. 1987), males and females show different patterns of cerebral development. Geschwind \& Galaburda (1985) have suggested that pre-natal testosterone may interfere with the proliferative processes involved in left hemisphere development, leaving the male more prone to developmental disorders affecting left hemisphere functions (see Chi et al. 1977; Goodman, 1990). 
Differences in cerebral organization between the sexes could also play a part in determining the gender differences in frequency of neurodevelopmental disorders. Specifically, males exhibit more lateralization of cerebral function than do females (McGlone, 1980). Such laterality differences affect not only the cortex, but also, in rats at least, the hippocampal-dentate complex (Diamond, 1989). It has been suggested that the male brain may consequently be less able to 'compensate' for those unilateral lesions considered important in the pathogenesis of schizophrenia (Seeman, 1982; Al-Issa, 1985).

\section{A CONFLATION OF TWO DISEASES?}

Family studies (Bellodi et al. 1986; Goldstein et al. 1989) have found that the morbid risk of schizophrenia in relatives of male schizophrenics is lower than that in relatives of female probands. Concordance rates for schizophrenia in monozygotic twins also appear lower in males than in females (Rosenthal, 1962; Kringlen, 1987). These data raise the possibility that schizophrenia in males is less heritable than in females.

One might go on to postulate that the overall preponderance of males in strictly-defined schizophrenic samples is due to a higher proportion of males having an illness in which early environmental influences have played a significant pathogenic role. Such reasoning could explain the excess of males among those schizophrenics who present early and exhibit pre-morbid dysfunction, negative features, and structural brain abnormality. It would not, however, explain the excess of women among those individuals who present after 30 and who are characterized by good pre-morbid functioning, positive rather than negative symptoms, more affective features, and better outcome.

\section{Female preponderance in later onset schizophrenia}

Later-onset patients are less likely to have a family history of schizophrenia (Kay \& Roth, 1961; Harris \& Jeste, 1988; Shimizu et al. 1988 b) or to have a history of obstetric complications (Reischies, 1989; Foerster et al. 1991 b). Furthermore, they are less likely to have been intellectually or occupationally compromised. For example, Johnstone et al. $(1989 \mathrm{~b})$, who dichotomized their 101 schizophrenic patients into those with early and late onset, noted that the latter group had performed better pre-morbidly in both academic and occupational spheres; they also had fewer negative symptoms and cognitive deficits. Noreik \& Odegaard (1966) analysed the incidence of mental illness in those who had graduated successfully from Norwegian high schools; males had a lower- and females a higher-than-expected rate of schizophrenia. Thus, among those individuals with adequate pre-morbid IQ and at least average academic capability, females are more at risk of later developing a psychosis conventionally diagnosed as 'schizophrenia'.

Stringent diagnostic criteria for schizophrenia, particularly those that discount patients with prominent affective symptomatology, exclude more women than men (Lewine et al. 1984; Katschnig \& Lenz, 1988). Furthermore, females are over-represented among cohorts of psychotic patients labelled 'atypical', 'schizoaffective', or 'cycloid': these groups contain patients with schizophreniform symptomatology, but a relatively benign longitudinal course (Tsuang et al. 1976; Cutting et al. 1978; Kendell, 1988; Levitt \& Tsuang, 1988). Together, these data beg the question of whether some females diagnosed as schizophrenic may suffer a different type of illness from that characteristic of males, or even whether many later-onset female 'schizophrenics' might actually be suffering from affective psychosis (Pope \& Lipinsky, 1978).

Family studies have shown an increased morbid risk of affective disorder in the relatives of schizophrenics with 'atypical' or schizoaffective features and good outcome (McCabe et al. 1971; Pope \& Lipinsky, 1978; Kendler \& Hays, 1983; De Lisi et al. 1987; Kendler \& Tsuang, 1988). These patients are also less likely to show ventricular enlargement on CT scan (Owen et al. 1989). The most parsimonious explanation for this, and for the better outcome in women, is that many cases of so-called later-onset schizophrenia in women have more in common, aetiologically, with affective 
psychosis than schizophrenia. It is, of course, well known that affective psychosis is more common in women than men (Boyd \& Weissman, 1981; Robins et al. 1984; Surtees \& Sashidharan, 1986).

\section{CONCLUSION}

Thus, we suggest that much of the contemporary confusion in schizophrenia is due to the conflation of two separate disorders. Kraepelin (1986) originally described dementia praecox as a severe chronic illness predominantly affecting young males. Almost a century later, it is becoming clear that Kraepelinian schizophrenia is indeed more common in young males, contingent upon their greater susceptibility to neurodevelopmental disorder. In contrast, the 'atypical' later-onset schizophrenia-like illnesses are commoner in women; the greater frequency of affective symptoms in such patients, their better outcome, and the higher risk of affective disorder in their relatives, suggests that they are aetiologically related to the affective psychoses.

DAVID J. CASTLE AND ROBIN M. MURRAY

We are grateful to Drs R. Goodman, E. O'Callaghan, A. Riecher, S. Lewis, and E. Hare for their helpful comments, and to the Psychiatry Research Trust and the Leverhulme Trust for financial support.

\section{REFERENCES}

Al-Issa, I. (1985). Sex differences in the aetiology of schizophrenia. International Review of Applied Psychology 34, 315-333.

Amato, M., Howald, H. \& von Muralt, G. (1987). Fetal sex and distribution of peri-ventricular hemorrhage in preterm infants. European Journal of Neurology 27, 20-23.

Andreasen, N. C., Dennert, J. W., Olsen, S. A. \& Damasio, A. R. (1982). Hemispheric asymmetries and schizophrenia. American Journal of Psychiatry 139, 427-430.

Andreasen, N. C., Nasrallah, H. A., Dunn, V., Olson, S. C., Grove, W. M., Ehrhardt, J. C., Coffman, J.A. \& Crossett, J. H.W. (1986). Structural abnormalities in the frontal system in schizophrenia: a magnetic resonance imaging study. Archives of General Psychiatry 43, 136-144.

Andereasen, N. C., Swayze, V. W., Flaum, M., Yates, W. R., Pahl, J. J., Arndt, S. \& McChesney, C. (1989). Ventricular enlargement in schizophrenia evaluated with $C T$ scanning. Paper presented at American Psychiatric Association Meeting, San Francisco.

Andrews, G. \& Harris, M. (1964). The syndrome of stuttering. Clinics in Developmental Medicine, number 17. Heinemann: London.

Angermeyer, M. C. (1985). Zur Frage geschlechtsabhängiger Unterschiede im Verlauf schizophrener Krankheit. Lecture given at the Central Institute of Mental Health, Mannheim.

Angermeyer, M. C. \& Kuhn, L. (1988). Gender differences in age at onset of schizophrenia: an overview. European Archives of Psychiatry and Neurological Sciences 237, 351-364.

Angermeyer, M. C., Goldstein, J. M. \& Kuehn, L. (1989). Gender differences in schizophrenia: rehospitalization and community survival. Psychological Medicine 19, 365-382.

Aylward, E., Walker, E. \& Bettes, B. (1984). Intelligence in schizophrenia: Meta-analysis of the research. Schizophrenia Bulletin 10, 430-459.

Babigian, H. M. (1975). Schizophrenia: epidemiology. In Comprehensive Textbook of Psychiatry, 2nd edn (ed. A. M. Freedman, H. Kaplan \& B. J. Sadock), pp. 861-866. Williams \& Wilkins: Baltimore.

Bellodi, L., Bussoleni, C., Scorza-Smeraldi, R., Grassi, G., Zacchetti, L. \& Smeraldi, E. (1986). Family study of schizophrenia: exploratory analysis for relevant factors. Schizophrenia Bulletin 12, $120-128$.

Bogerts, B., Meertz, E. \& Schonfeldt-Bausch, R. (1985). Basal ganglia and limbic system pathology in schizophrenia. Archives of General Psychiatry 42, 784-791.

Bogerts, B., Ashtari, M., Degreef, G., Alvir, J., Bilder, R. \& Lieberman, J. (1990a). Reduced temporal limbic structure volumes on magnetic resonance images in first episode schizophrenia. Psychiatry Research: Neuroimaging 35, 1-35.

Bogerts, B., Falkai, P., Haupts, M., Greve, B., Ernst, S., TapernonFranz, V. \& Heinzmann, W. (1990b). Post-mortem volume measurements of limbic system and basal ganglia structures in chronic schizophrenics. Schizophrenia Research (in the press).

Boyd, J. H. \& Weissman, M. M. (1981). Epidemiology of affective disorders: a re-examination and future directions. Archives of General Psychiatry 38, 1039-1046.

Broman, S., Nichols, P. L., Shaughnessy, P. \& Kennedy, W. (1987). Retardation in Young Children: A Developmental Siudy of Cognitive Deficit. Lawrence Erlbaum: Hillsdale, N.J.

Brown, R., Colter, N., Corsellis, J., Crow, T. J., Frith, C. D., Jagoe, R., Johnstone, E. C. \& Marsh, L. (1986). Post-mortem evidence of structural brain changes in schizophrenia. Archives of General Psychiatry 43, 36-42.

Bryson, S. E., Clark, B. S. \& Smith, I. M. (1988). First report of a Canadian epidemiological study of autistic syndromes. Journal of Child Psychology and Psychiarry 29, 433-445.

Chi, J. G., Dooling, E. C. \& Gilles, F. H. (1977). Gyral development of the human brain. Annals of Neurology 1, 86-93.

Cooper, J. E., Goodhead, D., Craig, T., Harris, M., Howat, J. \& Korer, J. (1987). The incidence of schizophrenia in Nottingham. British Journal of Psychiatry 151, 619-626.

Crow, T. J. (1985). The two-syndrome concept: origins and current status. Schizophrenia Bulletin 11, 471-485.

Crow, T. J., Ball, J., Bloom, S. R., Brown, R., Bruton, C. J., Colter, N., Frith, C. D., Johnstone, E. C., Owens, D. G. C. \& Roberts, G. W. (1989). Schizophrenia as an anomaly of development of cerebral asymmetry: a post-mortem study and a proposal concerning the genetic basis of the disease. Archives of General Psychiatry 46, 1145-1150.

Cutting, J. C., Clare, A. W. \& Mann, A. H. (1978). Cycloid psychosis: investigation of the diagnostic concept. Psychological Medicine 8, 637-648.

De Lisi, L. E., Goldin, L. R., Maxwell, M. E., Kazuba, D. M. \& Gershon, E. S. (1987). Clinical features of illness in siblings with schizophrenia or schizoaffective disorder. Archives of General Psychiatry 44, 891-896.

De Lisi, L. E., Dauphinais, I. D. \& Hauser, P. (1989). Gender differences in the brain: are they relevant to the pathogenesis of schizophrenia? Comprehensive Psychiatry 30, 197-208. 
Diamond, M. C. (1989). Sex and the cerebral cortex. Comprehensive Psychiatry 30, 823-825.

Dohrenwend, B. S. \& Dohrenwend, B. P. (1976). Sex differences in psychiatric disorders. American Journal of Sociology 81, 1447-1454.

Farina, A., Garmezy, N. \& Barry, H. (1963). Relationship of marital status to incidence and prognosis of schizophrenia. Journal of Abnormal Psychology 67, 624-630.

Flor-Henry, P. (1985). Schizophrenia: sex differences. Canadian Journal of Psychiatry 30, 319-322.

Foerster, A., Lewis, S. W., Owen, M. J. \& Murray, R. M. (1991 a). Pre-morbid personality in psychosis: effects of sex and diagnosis. British Journal of Psychiatry (in the press).

Foerster, A., Lewis, S. W., Owen, M. J. \& Murray, R. M. (1991 b) Low birth weight and a family history of schizophrenia predict poor pre-morbid functioning in psychosis. Schizophrenia Research (in the press).

Garmezy, N. (1974). Children at risk: the search for the antecedents of schizophrenia. I. Conceptual models and research methods. Schizophrenia Bulletin 8, 14-90.

Geschwind, N. \& Galaburda, A. M. (1985). Cerebral lateralisation : Biological mechanisms, associations, and pathology. I. A hypothesis and programme for research. Archives of Neurology $\mathbf{4 2}$, 428-459.

Gill, M., Taylor, C. \& Murray, R. M. (1989). Schizophrenia research : attempting to integrate genetics, neurodevelopment and nosology. International Review of Psychiatry 1, 277-286.

Goldberg, S. C., Schooler, N. R., Davidson, E. M. \& Kayce, M. M (1966). Sex and race differences in response to drug treatment among schizophrenics. Psychopharmacologica (Berlin) 9, 31-47.

Goldstein, J. M. \& Link, B. G. (1988). Gender and the expression of schizophrenia. Journal of Psychiatric Research 22, 141-155.

Goldstein, J. M., Tsuang, M. T. \& Faraone, S. V. (1989). Gender and schizophrenia : implications for understanding the heterogeneity of the illness. Psychiatry Research 28, 243-253.

Goldstein, J. M., Santangelo, S. L., Simpson, J. C. \& Tsuang, M. T. (1990). The role of gender in identifying subtypes of schizophrenia: a latent class analytic approach. Schizophrenia Bulletin 16, 263275.

Goldstein, M. J., Rodnick, E. H., Evans, J. R., May, P. R. A. \& Steinberg, M. R. (1978). Drug and family therapy in the aftercare of acute schizophrenics. Archives of General Psychiatry 35, 1169-1177.

Goodman, R. (1990). Developmental disorders and structural brain development. In Biological Risk Factors for Psychosocial Development (ed. M. Rutter \& P. Casaer). Cambridge University Press: Cambridge (in the press).

Government Statistical Office (1986). Statistical Bulletin of Department of Health and Social Security. HMSO: London.

Green, M. F., Satz, P., Gaier, D. J., Ganzell, S. \& Kharabi, F. (1989). Minor physical anomalies in schizophrenia. Schizophrenia Bulletin $15,91-99$.

Grimm, V. E. \& Frieder, B. (1985). Differential vulnerability of male and female rats to the timing of various perinatal insults. International Journal of Neuroscience 27, 155-164.

Gunderson, J. G. \& Siever, L. J. (1985). Relatedness of schizotypal to schizophrenic disorders. Schizophrenia Bulletin 11, 532-537.

Guy, J. D., Majorski, L. V., Wallace, C. J. \& Guy, M. P. (1983). The incidence of minor physical anomalies in adult male schizophrenics. Schizophrenia Bulletin 9, 571-582.

Haas, G. L., Sweeney, J. A., Keilp, J. \& Frances, A. J. (1989). Sex differences of neurocognition of schizophrenia. Paper presented at American Psychiatric Association Meeting, San Francisco.

Hadders-Algra, M., Touwen, B. C. \& Huisjes, H. J. (1986). Neurologically deviant newborns: neurological and behavioural development at the age of six years. Developmental Medicine and Child Neurology 28, 569-578.

Häfner, H. (1987). Epidemiology of schizophrenia. In Search for the Causes of Schizophrenia (ed. H. Häfner, W. F. Gattaz \& W. Janzarik), pp. 47-74. Springer-Verlag: Berlin.

Häfner, H., Riecher, A., Maurer, K., Löffler, W., Munk-Jørgensen, P. \& Strömgren, E. (1989). How does gender influence age at first hospitalisation for schizophrenia? A translational case register study. Psychological Medicine 19, 903-918.

Harris, M. J. \& Jeste, D. V. (1988). Late-onset schizophrenia: an overview. Schizophrenia Bulletin 14, 39-55.

Harvey, I., Williams, M., Toone, B. K., Lewis, S. W., Turner, S. W. \& McGuffin, P. (1990). The ventricular-brain ratio (VBR) in functional psychoses: the relationship of lateral ventricular and total intracranial area. Psychological Medicine 20, 55-62.

Jakob, H. \& Beckmann, H. (1986). Prenatal developmental disturbances in the limbic allocortex in schizophrenics. Journal of Neural Transmission 65, 303-326.

Johnstone, E. C., Owens, D. G. C., Crow, T. J., Frith, C. D., Alexanderopolis, K., Bydder, G. \& Colter, N. (1989a). Temporal lobe structure as determined by nuclear magnetic resonance in schizophrenia and bipolar affective disorder. Journal of Neurology, Neurosurgery, and Psychiatry 52, 736-741.

Johnstone, E. C., Owens, D. G. C., Bydder, G. M., Colter, N., Crow, T. J. \& Frith, C. D. $(1989 \mathrm{~b})$. The spectrum of structural brain changes in schizophrenia: age of onset as a predictor of cognitive and clinical impairments and their cerebral correlates. Psychological Medicine 19, 91-103.

Katsanis, J. \& lacono, W. G. (1989). Association of left-handedness with ventricle size and neuropsychological performance in schizo. phrenia. American Journal of Psychiatry 146, 1056-1058.

Katschnig, H. \& Lenz, G. (1988). Are sex differences in age at onset of schizophrenia related to phenomenological subtypes? Schizophrenia Research 1, 111-112.

Kay, D. W. K. \& Roth, M. (1961). Environmental and hereditary factors in the schizophrenias of old age ('late paraphrenia') and their bearing on the general problem of causation in schizophrenia. Journal of Mental Science 107, 649-686.

Kay, S. R., Opler, L. A. \& Fiszbein, A. (1986). Significance of positive and negative syndroms in chronic schizophrenia. British Journal of Psychiatry 149, 439-448.

Kendell, R. E. (1988). Other functional psychoses. In Companion to Psychiatric Studies (ed. R. E. Kendell \& A. K. Zealley), pp. 362-373. Churchill Livingstone: Edinburgh.

Kendler, K. S. (1985). Diagnostic approaches to schizotypal personality disorder: a historical perspective. Schizophrenia Bulletin 11, 538-553.

Kendler, K. S. \& Hays, P. (1983). Schizophrenia subdivided by the family history of affective disorder. Archives of General Psychiatry 40, 951-955.

Kendler, K.S. \& Tsuang, M. T. (1988). Outcome and familial psychopathology in schizophrenia. Archives of General Psychiatry 45, 338-346.

Klorman, R., Strauss, J. S. \& Kokes, R. F. (1977). Pre-morbid adjustment in schizophrenia: Ill. The relationship of demographic and diagnostic factors to measure of pre-morbid adjustment in schizophrenia. Schizophrenia Bulletin 3, 214-225

Kraepelin, E. (1896). Psychiatrie: ein Lehrbuch für Studirende und Aerzle. Barth: Leipzig.

Kringlen, E. (1987). Contributions of genetic studies on schizophrenia. In Search for the Causes of Schizophrenia (ed. H. Häfner, W. F. Gattaz \& W. Janzarik), pp. 123-143. Springer-Verlag: Heidelberg.

Levitt, J. J. \& Tsuang, M. T. (1988). The heterogeneity of schizoaffective disorder: implications for treatment. American Journal of Psychiatry 145, 926-936.

Lewine, R. J. (1981). Sex differences in schizophrenia: timing or subtypes? Psychological Bulletin 90, 432-444.

Lewine, R. J. (1988). Gender and schizophrenia. In Handbook of Schizophrenia, volume 3 (ed. H. A. Nasrallah), pp. 379-397. Elsevier: Amsterdam.

Lewine, R. J., Strauss, J. S. \& Gift, T. E. (1981). Sex differences in age at first hospital admission for schizophrenia : fact or artifact? American Journal of Psychiatry 138, 440-444.

Lewine, R. J., Burbach, D. \& Meltzer, H. Y. (1984). Effect of diagnostic criteria on the ratio of male to female schizophrenic patients. American Journal of Psychiatry 141, 84-87.

Lewine, R. J., Schwartzberg, D. G., Walker, E., Ninan, P. T., Risch, 
S. C. \& Houpt, J. L. (1989). Sex differences in brain structure and schizophrenia. Paper presented at American Psychiatric Association Meeting, San Fransisco.

Lewis, S. W. (1989). Congenital risk factors for schizophrenia. Psychological Medicine 19, 5-13.

Lewis, S. W. \& Murray, R. M. (1987). Obstetric complications, neurodevelopmental deviance, and risk of schizophrenia. Journal of Psychiatric Research 21, 413-421.

Lewis, S. W., Murray, R. M. \& Owen, M. (1988). Obstetric complications in schizophrenia: methodology and mechanisms. In Schizophrenia: A Scientific Focus (ed. C. A. Tamminga \& S. C. Schulz), pp. 56-59. Oxford University Press: New York.

Loranger, A. W. (1984). Sex difference in age at onset of schizophrenia. Archives of General Psychiatry 41, 157-161.

McCabe, M. S., Fowler, R. C., Cadoret, R. J. \& Winoker, G. (1971), Familial differences in schizophrenia with good and poor prognosis. Psychological Medicine 1, 326-332.

McGlone, J. (1980). Sex differences in human brain asymmetry: a critical survey. Behavioural and Brain Sciences 3, 215-263.

McNeil, T. F. (1988). Obstetric factors and perinatal injuries. In Handbook of Schizophrenia, Vol. 3 (ed. H. A. Nasrallah), pp. 319-344. Elsevier: Amsterdam.

Merrin, E. L. (1984). Motor and sighting dominance in chronic schizophrenics: relationship to social competence, age at first admission, and clinical course. British Journal of Psychiatry 145 , 401-406

Morstyn, R., Duffy, F. H. \& McCarley, R. W. (1983). Altered P300 topography in schizophrenia. Archives of General Psychiatry 40, 729-734.

Murray, R. M. \& Lewis, S. W. (1987). Is schizophrenia a neurodevelopmental disorder? British Medical Journal 295, 681-682.

Murray, R. M., Reveley, A. M. \& Lewis, S. W. (1988). Family history, obstetric complications and cerebral abnormality in schizophrenia. In Handbook of Schizophrenia, Vol. 3 (ed. H. A. Nasrallah), pp. 563-577. Elsevier: Amsterdam.

Nasrallah, H. A. \& Wilcox, J. A. (1989). Gender differences in the etiology and symptoms of schizophrenia: genetic versus brain injury factors. Annals of Clinical Psychiatry 1, 51-53.

Nasrallah, H. A., Keelor, K., Van Schroeder, C. \& Whitters, M. McC (1981). Motoric lateralisation in schizophrenic males. American Journal of Psychiatry 138, 1114-1115.

Nasrallah, H. A., Olson, S. C., McCalley-Whitters, M., Chapman, S. \& Jacoby, C. G. (1986). Cerebral ventricular enlargement in schizophrenia. A preliminary follow-up study. Archives of General Psychiatry 43, 157-159.

Nicole, L., Lesage, A. \& Lalonde, P. (1990). Gender differences in schizophrenia in Montreal. Paper presented at Schizophrenia 1990 Conference, Vancouver.

Nimgaonkar, V. L., Wessely, S. \& Murray, R. M. (1988). Prevalence of familiality, obstetric complications, and structural brain damage in schizophrenic patients. British Journal of Psychiatry 153, 191-197.

Noreik, K. \& Odegaard, O. (1966). Psychoses in Norwegians with a background of higher education. British Journal of Psychiatry 112, 43-55.

O'Callaghan, M. J., Tudehope, D. I., Dugdale, A. E., Mohay, H., Burns, Y. \& Cook, F. (1987). Handedness in children with birthweights below $1000 \mathrm{~g}$. Lancet i, 1155.

O'Callaghan, E., Larkin, C. \& Waddington, J. L. (1988). Clinical correlates of obstetric complications in schizophrenia. Schizophrenia Research 1, 125.

O'Callaghan, E., Larkin, C. \& Waddington, J. L. (1990). Obstetric complications in schizophrenia and the validity of maternal recall. Psychological Medicine 20, 89-94.

Offord, D. R. (1974). School performance of adult schizophrenics, their siblings and age mates. British Journal of Psychiatry 125, 12-19.

Offord, D. R. \& Cross, L. A. (1969). Behavioural antecedents of adult schizophrenia. Archives of General Psychiatry 21, 267-283.

Owen, M. J., Lewis, S. W. \& Murray, R. M. (1988). Obstetric complications and schizophrenia: a computed tomographic study. Psychological Medicine 18, 331-339.

Owen, M. J., Lewis, S. W. \& Murray, R. M. (1989). Family history and cerebral ventricular enlargement in schizophrenia: a case control study. British Journal of Psychiatry 154, 629-634.

Pearlson, G. D., Garbacz, D. J., Moberg, P. J., Ahn, H. S. \& de Paulo, J. R. (1985). Symptomatic, familial, perinatal, and social correlates of computerised axial tomography (CAT) changes in schizophrenia and bipolars. Journal of Nervous and Mental Disease 173, 42-50.

Pearlson, G. D., Kim, W. S., Kubos, K. L., Moberg, P. J., Jayaram, G., Bascom, M. J., Chase, G. A., Goldfinger, A. D. \& Tune, L. E. (1989). Ventricle-brain ratio, computed tomographic density, and brain area in 50 schizophrenics. Archives of General Psychiatry 46, 690-697.

Piran, N., Bigler, E. D. \& Cohen, D. (1982). Motoric laterality and eye dominance suggest unique pattern of cerebral organisation in schizophrenia. Archives of General Psychiatry 39, 1006-1010.

Pogue-Geile, M. F. \& Zubin, J. (1988). Negative symptomatology and schizophrenia : a conceptual and empirical review. International Journal of Mental Health 16, 3-45.

Pope, H. G. \& Lipinsky, J. F. (1978). Diagnosis in schizophrenia and manic depressive illness. Archives of General Psychiatry 35, 811-828.

Randall, P. L. (1983). Schizophrenia, abnormal connection, and brain evolution. Medical Hypotheses 10, 247-280.

Rantakallio, P. \& von Wendt, L. (1985). Prognosis for lowbirthweight infants up to the age of 14 : a population study. Developmental Medicine and Child Neurology 27, 655-663.

Reischies, F. M. (1989). Neuropsychology of the development of cognitive and emotional symptoms of schizophrenic patients using the connectivity model (personal communication).

Reveley, M. A. (1988). Cerebral Ventricular Size and Brain Density in Schizophrenia. M.D. thesis, University of London.

Reveley, M. A., Reveley, A. M. \& Baldy, R. (1987). Left hemisphere hypodensity in discordant schizophrenic twins: a controlled study. Archives of General Psychiatry 44, 625-632.

Reynolds, G. P. (1983). Increased concentrations and lateral asymmetry of amygdala dopamine in schizophrenia. Nature 305, 527-529.

Riecher, A., Maurer, K., Loffler, W., Fatkenheuer, B., an der Heiden, W. \& Häfner, H. (1989). Schizophrenia - a disease of young single males? European Archives of Psychiatry and Neurological Sciences 239, 210-212.

Rieder, R. O. \& Nichols, P. L. (1979). Offspring of schizophrenics. III. Hyperactivity and neurological soft signs. Archives of General Psychiatry 36, 665-674.

Rieder, R. O., Broman, S. H. \& Rosenthal, D. (1977). The offspring of schizophrenics. II. Perinatal factors and IQ. Archives of General Psychiatry 34, 789-799.

Robins, L. N., Helzer, J. E., Weissman, M. M., Orvaschel, H., Gruenberg, E., Burke, J. D. \& Regier, D. A. (1984). Lifetime prevalence of specific psychiatric disorders in three sites. Archives of General Psychiatry 41, 949-958.

Rosenthal, D. (1962). Familial concordance by sex with respect to schizophrenia. Psychological Bulletin 59, 401-421.

Rosenthal, D. (1970). Genetic Theory and Abnormal Behaviour. McGraw-Hill: New York.

Ross, G., Lipper, E. G. \& Auld, P. A. M. (1987). Hand preference of four-year-old children: its relationship to premature birth and neurodevelopmental outcome. Developmental Medicine and Child Neurology 29, 615-622.

Rutter, M. \& Tizard, J. (1970). Intellectual and educational retardation : prevalence and cognitive characteristics. In Education, Health and Behaviour (ed. M. Rutter, J. Tizard \& K. Whitmore), pp. 39-53. Longman: London.

Sartorius, N., Jablensky, A., Korten, A., Ernberg, G., Anker, M., Cooper, J. E. \& Day, R. (1986). Early manifestations and firstcontact incidence of schizophrenia in different cultures. Psychological Medicine 16, 909-928. 
Satz, P. (1972). Pathological left-handedness: an explanatory model. Cortex 8, 121-135.

Seeman, M. V. (1982). Gender differences in schizophrenia. Canadian Journal of Psychiatry 27, 107-111.

Seeman, M. V. (1983). Interaction of age, sex and neuroleptic dose. Comprehensive Psychiatry 24, 125-128.

Seeman, M. V. (1985). Sex and schizophrenia. Canadian Journal of Psychiatry 30, 313-315.

Seeman, M. V. (1986). Current outcome in schizophrenia: women vs men. Acta Psychiatrica Scandinavica 73, 609-617.

Seeman, M. V. (1989). Prenatal gonadal hormones and schizophrenia in men and women. Psychiatric Journal of The University of Ottawa 14, 473-475.

Shelton, R. C. \& Weinberger, D. R. (1986). X-ray computerised tomography studies in schizophrenia: a review and synthesis. In The Neurology of Schizophrenia (ed. H. A. Nasrallah \& D. R. Weinberger), pp. 207-250. Elsevier: Amsterdam.

Shepherd, M., Watt, D., Falloon, I. \& Smeeton, N. (1989). The Natural History of Schizophrenia: A Five-Year Follow-up Study of Outcome and Prediction in a Representative Sample of Schizophrenics. Psychological Medicine, Supplement 15.

Shimizu, A., Kurachi, M., Noda, M., Yamaguchi, N., Torri, H. \& Isaki, K. (1988a). Influence of sex on age at onset of schizophrenia. Japanese Journal of Psychiatry and Neurology 42, 35-40.

Shimizu, A., Kurachi, M., Yamaguchi, N., Torii, H. \& Isaki, K. $(1988 b)$. Does family history of schizophrenia influence age at onset of schizophrenia? Acta Psychiarrica Scandinavica 78, 716-719.

Strömgren, E. (1987). Changes in the incidence of schizophrenia? British Journal of Psychiarry 150, 1-7.

Suddath, R. L., Christison, G. W., Torrey, E. F., Casanova, M. F. \& Weinberger, D. R. (1990). Anatomical abnormalities in the brains of monozygotic twins discordant for schizophrenia. New England Journal of Medicine 322, 789-794.

Surtees, P. G. \& Sashidharan, S. P. (1986). Psychiatric morbidity in two matched community samples: a comparison of rates and risks in Edinburgh and St Louis. Journal of Affective Disorders 10, $101-113$.

Taylor, D. C. (1969). Differential rates of cerebral maturation between the sexes and between hemispheres. Lancet ii, 140142.

Thatcher, R. W., Walker, R. A. \& Giudice, S. (1987). Human cerebral hemispheres develop at different rates and ages. Science 236, 1110-1113.

Tsuang, M. T., Dempsey, G. M. \& Rauscher, F. (1976). A study of 'atypical schizophrenia': comparison with schizophrenia and affective disorder by sex, age of admission, precipitant, outcome, and family history. Archives of General Psychiatry 33, 1157-1160.

Turner, S. W., Toone, B. K. \& Brett-Jones, J. R. (1986). Computerised tomographic scan changes in early schizophrenia: preliminary findings. Psychological Medicine 16, 219-225.

Vita, A., Sacchetti, E., Calzeroni, A. \& Cazzullo, C. L. (1988). Cortical atrophy in schizophrenia: prevalence and associated features. Schizophrenia Research 1, 329-337.

Waddington, J. L., O'Callaghan, E. \& Larkin, C. (1990). Physical anomalies and neurodevelopmental abnormality in schizophrenia: new clinical correlates. Schizophrenia Research 3, 90.

Weinberger, D. R. (1987). Implications of normal brain development for the pathogenesis of schizophrenia. Archives of General Psychiatry 44, 660-669.

Wilcox, J.A. \& Nasrallah, H. A. (1987). Perinatal distress and prognosis of psychotic illness. Neuropsychobiology 17, 173-175.

Wing, L. (1981). Asperger's Syndrome. Psychological Medicine 11, $115-129$.

Wolff, S. \& Chick, J. (1980). Schizoid personality in childhood: a controlled follow-up study. Psychological Medicine 10, 85-100.

Yu, V. Y. H., Loke, H. L., Bajuk, B., Szymonowicz, W., Orgill, A. A. \& Astbury, J. (1986). Prognosis for infants born at 23 to 28 weeks' gestation. British Medical Journal 293, 1200-1203.

Zeitlin, H. (1986). The Natural History of Psychiatric Disorder in Children. Oxford University Press: New York.

Zigler, E. \& Levine, J. (1973). Pre-morbid adjustment and paranoidnonparanoid status in schizophrenia: a further investigation. Journal of Abnormal Psychology 82, 189-199.

Zigler, E., Levine, J. \& Zigler, B. (1977). Pre-morbid social competence and paranoid-nonparanoid status in female schizophrenic patients. Journal of Nervous and Mental Disease 164, 333-339. 